Edith Seligmann-Silva ${ }^{1}$

Márcia Hespanhol Bernardo²

Maria Maeno ${ }^{3}$

Mina Kato ${ }^{4}$

\section{Saúde do Trabalhador no início do século XXI}

\author{
Worker's Health in the beginning of the 21st century
}

${ }^{1}$ Editora convidada, Universidade de São Paulo, São Paulo, SP.

2 Editora convidada, Pontifícia Universidade Católica, Campinas, SP.

${ }^{3}$ Editora convidada, Fundacentro, São Paulo, SP.

${ }^{4}$ Editora associada, Fundacentro, São Paulo, SP.
Embora a relação trabalho e saúde tenha sido relatada desde a Antiguidade, as primeiras abordagens formais desta relação tiveram início na Europa, no século XIX, com a criação da Medicina do Trabalho e a implantação dos serviços médicos dentro das empresas. Eram estruturas centradas na figura do médico, que, por meio de uma atuação focada no trabalhador, assumiam a responsabilidade pela prevenção dos acidentes e das doenças. Mas o interesse principal não era o de promover a saúde dos trabalhadores, mas, sim, o bom funcionamento dos processos de trabalho. As práticas mais disseminadas eram a seleção de pessoal que, em tese, fosse menos propenso a se acidentar e adoecer, o controle da saúde para evitar problemas de absenteísmo e os esforços para proporcionar retorno rápido ao trabalho nos casos de afastamentos.

A Organização Internacional do Trabalho (OIT), criada em 1919, adotou, desde o início, normas preventivas que tratavam da limitação da jornada, do desemprego, da proteção à maternidade, do trabalho noturno de menores e mulheres e da idade mínima para admissão de crianças. Em 1953, por meio da Recomendação 97, sobre a proteção à saúde dos trabalhadores, passou a estimular os países membros a formarem seus médicos do trabalho e a instalarem serviços de Medicina do Trabalho nas empresas. No Brasil, desde 1943, com a Consolidação das Leis do Trabalho e com a Lei no 6.514, de 1977, tais serviços foram previstos e o ambiente no espaço das empresas passou a ser objeto de atenção da Engenharia de Segurança e da Higiene Ocupacional, com a entrada em cena, de forma mais enfática, de profissionais das áreas de Engenharia e Toxicologia.

A atuação dos médicos sempre se pautou pela avaliação de elementos objetivos que pudessem, de alguma forma, interferir na integridade física e na saúde do trabalhador, assim como a dos engenheiros e dos toxicologistas sempre teve como objeto de avaliação e intervenção as condições de trabalho visíveis e mensuráveis. No entanto, a observação e a evolução do perfil de adoecimento dos trabalhadores têm denunciado outros elementos não abordados pelo tradicional sistema de prevenção de acidentes e doenças das empresas.

Nas décadas de 1980 e 1990, concomitantemente aos já conhecidos agravos ocupacionais, com mortes e mutilações, intoxicações por vários produtos químicos, perdas auditivas, pneumopatias e dermatoses, os trabalhadores com afecções musculoesqueléticas, as LER/DORT, passaram a invadir os consultórios. Diferentemente de outros agravos, esses ocorriam indistintamente entre trabalhadores da indústria, do comércio e de serviços. Acometiam trabalhadores cujas atividades laborais não exigiam altos gastos energéticos e sua etiologia não podia ser enquadrada nos fatores de risco tradicionais: físicos, químicos e biológicos. Nesse con- 
texto, ganhou força a discussão de que o trabalho e suas repercussões sobre a saúde dos trabalhadores deveriam ser analisados não somente no tocante às condições tradicionalmente abordadas, mas também aos seus aspectos organizacionais, ergonômicos e psicossociais.

Mais recentemente, sobretudo nas décadas de 1990 e 2000, outro aspecto da saúde dos trabalhadores passou a ganhar espaço nos consultórios. São as repercussões psíquicas do trabalho, com expressões clínicas correspondentes a vários diagnósticos presentes na Classificação Internacional de Doenças (CID-10) e reconhecidos como relacionados ao trabalho tanto pelo Ministério da Saúde (Portaria no 1339/GM, de 18 de novembro de 1999), como pelo Ministério da Previdência Social (Decreto no 3048, de 1999). Esses agravos à saúde, que até então não eram identificados, também evidenciam a complexidade que envolve a avaliação da relação entre o processo saúde/doença e o trabalho.

Setores da Saúde, do Trabalho, do Judiciário, do Ministério Público, das universidades e dos órgãos de pesquisa começaram a ter suas agendas pautadas por sindicatos e outras entidades representativas dos trabalhadores, que observavam um contingente crescente de pessoas com transtornos psíquicos, os quais frequentemente não conseguiam permanecer trabalhando pelas condições adversas das empresas e que não raramente eram isoladas e demitidas. Essa demanda provocou indagações, estudos e ações que reforçaram de forma indubitável aquilo que o advento das LER/DORT já havia desnudado: a insuficiência dos recursos da medicina do trabalho, da engenharia de segurança e da higiene ocupacional para se construir políticas públicas de promoção da saúde, prevenção, assistência e reabilitação profissional.

Assim, não temos dúvidas de que a construção de alternativas de processos de trabalho que protejam a saúde do trabalhador exige diálogo e ação conjunta dos campos da Medicina, da Psicologia e de outros setores da saúde, da Engenharia, da Ergonomia, da Sociologia, da Antropologia, da Filosofia, do Direito, da Economia e outros. Esse diálogo tem tomado corpo, ainda de forma incipiente, em intervenções nos ambientes de trabalho, em ações civis públicas, em publicações e eventos com abordagens mais amplas e contextualizadas, e mostram claramente que está esgotado o modelo de intervenção de disciplinas e campos de conhecimento isoladamente. Os agravos em geral, e os adoecimentos psíquicos em particular, devem ter como pano de fundo os aspectos sociais e do trabalho contemporâneo, caracterizados pela perda de direitos sociais e trabalhistas, pelo advento de crises econômicas e do desemprego.

A Revista Brasileira de Saúde Ocupacional, com o dossiê temático "O mundo contemporâneo do trabalho e a saúde mental do trabalhador", sendo este seu primeiro volume, espera contribuir com o esforço de reunir pesquisas, reflexões e experiências que, compartilhadas por atores de diferentes instituições e entidades, possam estimular a discussão e a construção de políticas públicas que levem em consideração a Saúde do Trabalhador, incluindo seus aspectos biológicos e psicossociais, no processo de desenvolvimento econômico e social de nosso país. 